\title{
Association of Peripheral Neuropathy in Chronic Kidney Disease (CKD)
}

\author{
Dr Hafiz Kazim Hassan ${ }^{1} \quad$ Dr Maria Iqbal Khan ${ }^{1} \quad$ Dr Tayyeb Umer ${ }^{2}$ \\ 1.Mayo Hospital and Lady Willingdon Hospital, Lahore \\ 2..Nishtar Hospital, Multan
}

\begin{abstract}
Objective: To study the prevalence of peripheral neuropathy and evaluate the clinical nerve dysfunction in patients with chronic kidney disease. Study Design: Prospective study Place and duration: Medical ward Mayo hospital, Lady Wllingdon Hospital and Nishtar Hospital Multan from March 2018 to May 2019. Methodology: Eighty patients of clinically and biochemically proven chronic kidney disease were selected for study. Non probability consecutive sampling was used. Patients were assessed or both sensory and motor nerve dysfunction. SPSS software was used for data analysis. Main variables of study were creatinine clearance and neuropathy of peripheral nerves. Results: Affected patients percentage with reference to overt and subclinical neuropathy was noted as $67.5 \%$. Overt neuropathy and subclinical neuropathy observed as $35.2 \%$ and $64.8 \%$, respectively. Patients affected with percentage with reference to the type of peripheral neuropathy were noted $67.5 \%$. Sensory-motor, sensory and motor was observed as 31.5\%, 14.8\% and 53.7\%, respectively. Conclusion: Peripheral neuropathy is highly associated with chronic kidney disease and severity and prevalence of neuropathy increases with worsening in renal failure. Early diagnosis and strict compliance required to overcome this condition.
\end{abstract}

Keywords: Chronic Kidney disease, Peripheral neuropathy, Hemodialysis, Sensory nerve, Motor nerve.

DOI: $10.7176 / \mathrm{JMPB} / 60-03$

Publication date:October $31^{\text {st }} 2019$

\section{Introduction}

Chronic kidney disease is associated with peripheral neuropathy ${ }^{1}$. Generally, patients would not come for examination of dysfunction of peripheral nerve supply until they looked for or asked for. Now in these days' patients long term survival rate is improving because of latest advancement in medical treatment ${ }^{2}$. Recent improvement in CKD management with hemodialysis, peritoneal dialysis and transplant brought revolution. Lifespan of patients also improved due to latest treatment improvement ${ }^{3}$.

It is essential to know about complications of CKD, if patients survive for long time, peripheral neuropathy is one of common complications of $\mathrm{CKD}^{4}$. Neuropathy in CKD is treatable. Signs and symptoms of CKD are in all cases but cases are different in nature ${ }^{5}$. Neuropathy is symmetrical, distal and mixed motor and sensory in nature affecting 65\% CKD patients mostly lower limbs as compared to upper limb. Strict control on patient's serum creatinine with on time dialysis and medical compliance reversal and progression of neuropathy is possible ${ }^{6}$.

Peripheral neuropathy develops in male patients is greater than female and this difference is unexplained yet ${ }^{7}$. Intensity of disease and chronicity are main contributing features in peripheral neuropathy ${ }^{8}$. Existence of peripheral neuropathy clearly suspected and described in previous literature but metabolic disturbance of CKD and its dominated state of coma was not explained with its chronicity ${ }^{9,10}$. Many reports were conducted on this topic but no local study is available, so in this study incidence and severity of nerve dysfunction was assumed in CKD patients to fulfill the local reference gap.

\section{Methodology}

This prospective study was conducted at Medical ward Mayo hospital, Lady Wllingdon Hospital and Nishtar Hospital Multan from March 2018 to May 2019 after obtaining permission from hospital ethical board. Written consent was obtained from patients after detail information of study. Non probability consecutive sampling was used for data collection. Clinically and biochemically diagnosed cases of CKD were included in the study patients with serum creatinine $>2 \mathrm{mg}$, do not on dialysis and creatinine clearance $<40 \mathrm{ml} / \mathrm{mt}$ were included. Patience with other contributing factors of peripheral neuropathy like diabetes was excluded from the study.

Electrophysiological tests were performed for sensory and motor neuropathy. Median right ulnar, tibial nerve, common peronal and sural nerve supply was tested. All neurological and liver related findings were noted. SPSS version 23 was used for data analysis mean and SD was calculated for numerical values and frequencies (percentages) were calculated for qualitative data. P value less than or equal to 0.05 was taken as significant.

\section{Results}

Eighty patients were included in this study, both genders. Gender distribution revealed as $n=54(67.5 \%)$ males and $\mathrm{n}=26(32.5 \%)$ females. (Figure. I). The mean duration of CKD was $3.87 \pm 1.89$ years. The distribution of CKD verses peripheral nerve dysfunction was shown in table I. 
Affected patients with percentage with reference to overt and subclinical neuropathy was noted as $\mathrm{n}=54$ (67.5\%). While, overt neuropathy and subclinical neuropathy observed as $n=19(35.2 \%)$ and $n=35(64.8 \%)$, respectively. Patients affected with percentage with reference to the type of peripheral neuropathy was noted $n=54$ $(67.5 \%)$. While, sensory-motor, sensory and motor were observed as $n=17(31.5 \%), n=8(14.8 \%)$ and $n=29$ $(53.7 \%)$, respectively. (Table. II).

The mean creatinine clearance $14.33 \pm 4.81 \mathrm{ml} / \mathrm{mt}$. Distribution of male and female patients affected with reference to creatinine clearance was shown in table III.

Table. I

Distribution of peripheral nerve dysfunction in CKD patients versus duration of disease

\begin{tabular}{|l|c|c|}
\hline Duration of CKD (year) & No. of patients with \% & Peripheral Nerve Dysfunction \\
\hline$<\mathbf{1}$ & $\mathrm{n}=17(21.3 \%)$ & $\mathrm{n}=13(76.5 \%)$ \\
\hline $\mathbf{1 - 3}$ & $\mathrm{n}=28(35 \%)$ & $\mathrm{n}=19(67.9 \%)$ \\
\hline $\mathbf{3 - 5}$ & $\mathrm{n}=20(25 \%)$ & $\mathrm{n}=14(70 \%)$ \\
\hline$>\mathbf{5}$ & $\mathrm{n}=15(18.8 \%)$ & $\mathrm{n}=9(60 \%)$ \\
\hline Total & $\mathbf{n}=\mathbf{8 0}(\mathbf{1 0 0 \% )}$ & $\mathbf{n}=\mathbf{5 5}(\mathbf{6 8 . 8 \%})$ \\
\hline
\end{tabular}

Table. II

\begin{tabular}{|l|c|}
\hline Variable & $\mathbf{N}, \mathbf{( \% )}$ \\
\hline Patients affected with percentage with reference to overt and subclinical neuropathy \\
\hline Overt neuropathy & $\mathrm{n}=19(35.2 \%)$ \\
\hline Subclinical neuropathy & $\mathrm{n}=35(64.8 \%)$ \\
\hline Total & $\mathrm{n}=54(67.5 \%)$ \\
\hline Patients affected with percentage with reference to the type of peripheral neuropathy \\
\hline Sensory-motor & $\mathrm{n}=17(31.5 \%)$ \\
\hline Sensory & $\mathrm{n}=8(14.8 \%)$ \\
\hline Motor & $\mathrm{n}=29(53.7 \%)$ \\
\hline Total & $\mathrm{n}=54(67.5 \%)$ \\
\hline
\end{tabular}

Table. III

Distribution of male and female patients affected with reference to creatinine clearance

\begin{tabular}{|l|c|c|}
\hline Creatinine clearance $\mathbf{~ m l} / \mathbf{m t}$ & Male & Female \\
\hline$<\mathbf{1 5}$ & $\mathrm{n}=30(75 \%)$ & $\mathrm{n}=10(25 \%)$ \\
\hline $\mathbf{2 6 - 2 9}$ & $\mathrm{n}=14(60.9 \%)$ & $\mathrm{n}=9(39.1 \%)$ \\
\hline $\mathbf{3 0 - 5 9}$ & $\mathrm{n}=10(58.8 \%)$ & $\mathrm{n}=7(41.2 \%)$ \\
\hline Total & $\mathbf{n}=\mathbf{8 0}(\mathbf{1 0 0} \%)$ & $\mathbf{n}=\mathbf{5 5}(\mathbf{6 8 . 8 \%})$ \\
\hline
\end{tabular}

Figure. I

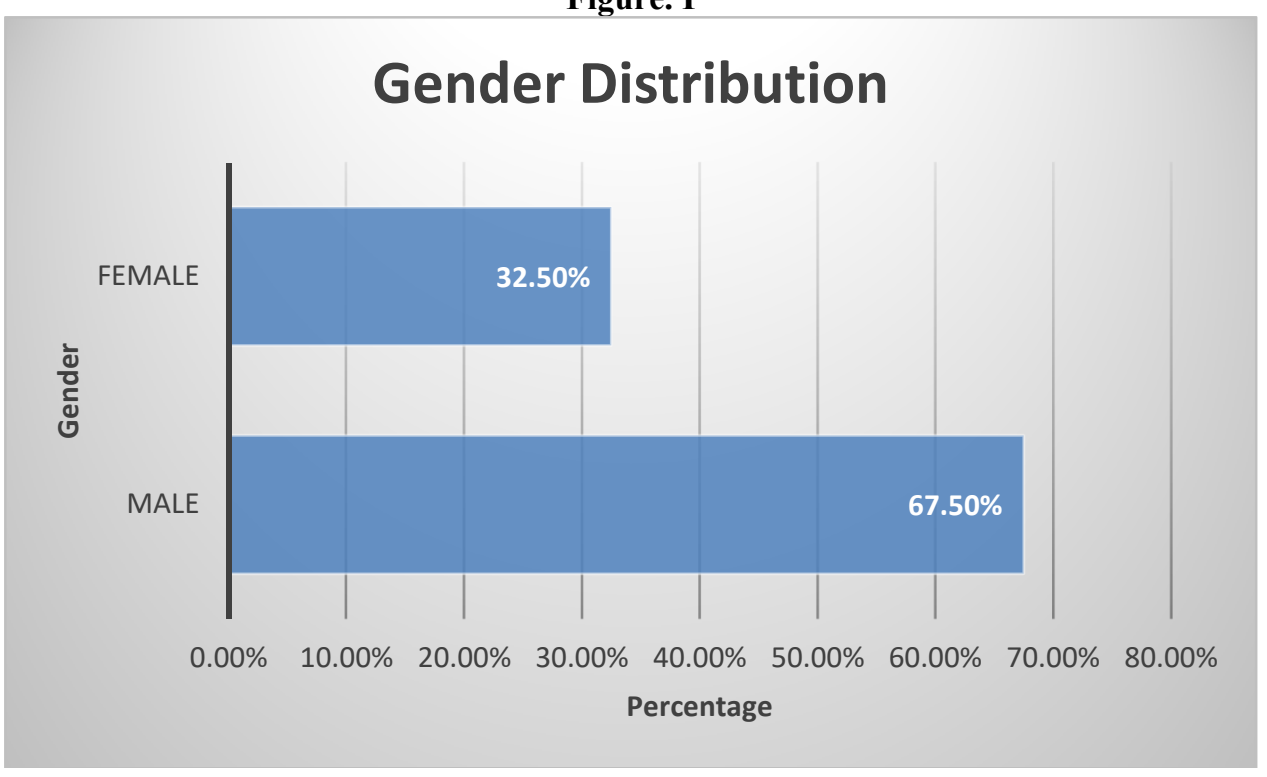




\section{Discussion}

Common and recognized complication of CKD is peripheral neuropathy. It may lead to peripheral nervous system, morbidity and mortality. Renal derangement is the contributing factor of neuropathy ${ }^{11}$. In a study conducted by Sultan et $\mathrm{l}^{12}$ reported that renal derangement or CKD effect the nervous system. Peripheral neuropathy is the complication of CKD.

In a study conducted by Kumar et $\mathrm{al}^{13}$ and concluded the involvement of CKD in disturbance of neurological system. Neuropathy is the main complication. He also reported that severity of disease has import on patient's neurological condition. Sensory neuropathy was $34 \%$ and motor neuropathy was $16 \%$ observed.

Babu et $\mathrm{al}^{14}$ conducted a study on this topic and focused on association of CKD and peripheral neuropathy. In that study impact of age was also observed on neuropathy and its severity. Age $>65$ years is more prove to peripheral neuropathy in CKD. Rathankumar et $\mathrm{al}^{15}$ completed a study in 2018 on peripheral dysfunction and CKD and conclude that distal sensory and motor neuropathy our two common types of peripheral neuropathy associated with CKD. In that study $64.8 \%$ of patients have peripheral neuropathy. Male patients with creatinine clearance having less that $15 \mathrm{ml} / \mathrm{mt}$ are on greater risk.

Another study was conducted by Arnold et $\mathrm{a}^{16}$ reported that CKD is highly associated with neurological complications which may lead to sourobidity and neutrality. May chronic neurological complications like stroke, dementia and cognitive impairment were also observed.

In a study by Bolton et $\mathrm{al}^{17}$ observed similar findings and reported that a number of peripheral neurological disorders are associated with CKD. Cause behind this pathology is production of toxins in CKD. Renal transplantation is an option for its recovery. Another study was conducted by Nielsen et al ${ }^{18}$ and concluded that $77 \%$ patients with CKD have peripheral neuropathy and remaining have signs of peripheral neuropathy. In that study slowing of nerve conduction was observed in patient with renal derangement since last 2 years.

Aggarwal et a $1^{19}$ conducted a study on peripheral neuropathy in CKD patients and reported that sensory and motor neuropathies are associated with severity of disease or renal function; he observed symptomatic neuropathy in $51 \%$ of predialysis patients. Similar study was conducted by Krishnan et $\mathrm{al}^{20}$ in 2005 and reported $91 \%$ peripheral neuropathy in chronic kidney disease. This association was reported irreversible that cannot be reversed with early or delayed recovery from renal derangement.

\section{Conclusion}

Peripheral neuropathy is highly associated with chronic kidney disease and severity and prevalence of neuropathy increases with worsening in renal failure. Early diagnosis and strict compliance required to overcome this condition.

\section{References}

1. Chillon JM, Massy ZA, Stengel B. Neurological complications in chronic kidney disease patients. Nephrol Dial Transplant. 2016;31:1606-14.

2. Masson P, Webster AC, Hong M. Chronic kidney disease and the risk of stroke: a systematic review and metaanalysis. Nephrol Dial Transplant. 2015;30:1162-69.

3. Dad T, Weiner DE. Stroke and chronic kidney disease: epidemiology, pathogenesis, and management across kidney disease stages. Semin Nephrol. 2015;35:311-22.

4. O'Lone E, Connors M, Masson P. Cognition in people with end-stage kidney disease treated with hemodialysis: a systematic review and meta-analysis. Am J Kidney Dis. 2016;67:925-35.

5. Salman IM . Cardiovascular autonomic dysfunction in chronic kidney disease: a comprehensive review. Curr Hypertens Rep. 2015;17:59-59.

6. Jin SH, Park YS, Park YH, Chang HJ, Kim SR. Comparison of Gait Speed and Peripheral Nerve Function Between Chronic Kidney Disease Patients with and Without Diabetes. Ann Rehabil Med. 2017;41(1):72-79.

7. Kutner NG, Zhang R, Huang Y, Painter P. Gait speed and mortality, hospitalization, and functional status change among hemodialysis patients: a US renal data system special study. Am J Kidney Dis. 2015;66:297304.

8. Faiman B, Doss D, Colson K, Mangan P, King T, Tariman JD. Renal, GI, and Peripheral Nerves: EvidenceBased Recommendations for the Management of Symptoms and Care for Patients With Multiple Myeloma. Clin J Oncol Nurs. 2017;21(5 Suppl):19-36.

9. Moorthi RN, Doshi S, Fried LF. Chronic kidney disease and peripheral nerve function in the Health, Aging and Body Composition Study. Nephrol Dial Transplant. 2019;34(4):625-32.

10. Lange-Maia BS, Newman AB, Cauley JA. Sensorimotor peripheral nerve function and the longitudinal relationship with endurance walking in the Health, Aging and Body Composition Study. Arch Phys Med Rehabil. 2016; 97: 45-52.

11. Campese V, Romoff M, Lavitan D, Lane K, Massry S. Mechanisms of autonomic nervous system dysfunction in Uremia. J Urol. 1982;127:405.

12. Sultan LI. Evaluation of the clinical and neurophysiologic parameters of peripheral nerve functions in uremic 
Egyptian patients. Egypt J Neurol Psychiatr Neurosurg. 2007;44:473-87.

13. Kumar A, Prasad A, Dutta A, Roohi F. Study of nerve conduction velocity In tibial nerve of healthy male and female of different age groups. Int J Recent Sci Res. 2015;6:4477-82.

14. Madhusudhana Babu M, Ravi Kiran M, Ravindra K, Srinivas V, Kandregula P, Vikram Vardhan R. Clinical manifestations and prevalence of peripheral neuropathy and nerve dysfunction in patients with chronic kidney disease. Int J Res Med Sci. 2015;3:451-5.

15. Rathnakumar G, Jose JP, Anandan H. Peripheral Nerve Dysfunction in Chronic Kidney Disease. Int J Sci Stud. 2018;5(10):123-25.

16. Arnold R, Pussell BA, Pianta TJ. Association between calcineurin inhibitor treatment and peripheral nerve dysfunction in renal transplant recipients. Am J Transplant. 2013; 13: 2426-32.

17. Bolton CF, Baltzan MA, Baltzan RB. Effects of renal transplantation on uremic neuropathy. A clinical and electrophysiologic study. N Engl J Med. 1971;284:1170-5.

18. Nielsen VK. The peripheral nerve function in chronic renal failure. II. Intercorrelation of clinical symptoms and signs and clinical grading of neuropathy. Acta Med Scand. 1971;190:113-7.

19. Aggarwal HK, Sood S, Jain D, Kaverappa V, Yadav S. Evaluation of spectrum of peripheral neuropathy in predialysis patients with chronic kidney disease. Ren Fail. 2013;35:1323-9.

20. Krishnan AV, Phoon RK, Pussell BA, Charlesworth JA, Bostock H, Kiernan MC, et al. Altered motor nerve excitability in end-stage kidney disease. Brain. 2005;128:2164-74. 